\title{
Chemical Vapour Generation for Tin Determination in High-content Calcium Matrix by Inductively Coupled Plasma Atomic Emission Spectrometry
}

\author{
Sanda Rončević, ${ }^{\text {a,* }}$ Ivan Nemet, ${ }^{a}$ Lovorka Pitarević Svedružić, ${ }^{a}$ and Davorin Medakovićc \\ ${ }^{a}$ Laboratory of Analytical Chemistry, Department of Chemistry, Faculty of Science, University of Zagreb, \\ Horvatovac 102a, HR-10000, Zagreb, Croatia \\ ${ }^{\mathrm{b}}$ Center for Marine Research, Ruđer Bošković Institute, G. Paliage 5, HR-52210, Rovinj, Croatia
}

RECEIVED MARCH 21, 2013; REVISED NOVEMBER 7, 2013; ACCEPTED NOVEMBER 25, 2013

\begin{abstract}
Chemical vapour generation by reduction with sodium tetraborohydride and coupled to inductively coupled plasma spectrometry (HG-ICP-AES) was examined for tin analysis in high-content calcium matrix samples. Comparison of calibration curves in aqueous and matrix-matched solution showed good linearity $\left(R^{2}=0.9951-0.9999\right)$ in the observed range of concentration. The effects of added calcium were established as attenuation of emission intensity for $3 \%$ at $224.605 \mathrm{~nm}$ and $235.484 \mathrm{~nm}$ and only $1 \%$ at $283.999 \mathrm{~nm}$ and $189.991 \mathrm{~nm}$ of tin lines. The best limit of detection, i.e. $1.9 \mathrm{mg} \mathrm{L}^{-1}$ in aqueous and $2.1 \mathrm{mg}$ $\mathrm{L}^{-1}$ in matrix-matched solution were obtained at $189.991 \mathrm{~nm}$. Method of standard addition was applied for the analysis of laboratory samples of high purity calcite and aragonite shell structures and it gave $0.11 \mu \mathrm{g}$ $\mathrm{g}^{-1}$ and $0.17 \mu \mathrm{g} \mathrm{g}^{-1}$ of tin, respectively. The accuracy of method was tested by certified reference material (NRCC, MESS-3) and good recoveries (100.08 \%) were obtained in both calibration modes. Tin content was determined by HG-ICP-AES method using matrix-matched calibration in shell samples of Mytilus galloprovinciallis. The obtained values of tin content showed relatively flat distribution in shells along the coast $\left(0.511-0.718 \mu \mathrm{g} \mathrm{g}^{-1}\right)$. Higher concentrations were measured on several hotspots, especially fishing ports and harbours. (doi: 10.5562/cca2259)
\end{abstract}

Keywords: calcium matrix, hydride generation, ICP-AES, tin, shell analysis

\section{INTRODUCTION}

Atomic spectrometry methods based on absorption or emission of electromagnetic radiation combined with optical or mass spectrometers are firmly established in elemental analysis of environmental samples and biological tissues. ${ }^{1}$ Analytical performances of inductively coupled plasma atomic emission spectrometry (ICP-AES) allow simultaneous measurements of numerous elements and more emission lines of the particular element. However, interference effects in direct measurements of real sample solutions were not avoided completely, especially those caused by complex matrix. Quantitative determination of elements present at very low concentration range in calcium matrix is concerning and unpleasant analytical task which predicts a whole separate study of the calcium interference effects in plasma. It is already known that the high content calcium matrices produce either rising or reducing element emission line intensity in plasma. The nature of calcium effects were for the first time described by Thompson and
Ramsey who found strong correlation of interferences with excitation and ionization energy for observed elements. ${ }^{2}$ High calcium content matrix effects in plasma were studied recently by modern echelle spectrometers. Paama and Peramaki have determined several elements in calcite mortars and established effects of $\mathrm{Ca}^{3}{ }^{3}$ They found that $\mathrm{Ca}$ influenced measured concentrations up to $2 \%$ when it was present in concentration range higher than $600 \mathrm{mg} \mathrm{L}^{-1}$, and up to $1 \%$ in concentration range of 100 $200 \mathrm{mg} \mathrm{L}^{-1}$. Stepan et al. found that depressive effect of $\mathrm{Ca}$ on ionic and atomic lines could be minimized with robust plasma conditions i.e. higher power and lower carrier gas flow. ${ }^{4}$ However, matrix matching or internal standardization is recommended in the case of metal analysis in high content $\mathrm{Ca}$ solutions. ${ }^{5}$

The technique of hydride generation with inductively coupled plasma optical emission spectrometry (HG-ICP-AES) is widely used to enhance the sensitivity of metal determination and to eliminate the majority of matrix interferences in plasma. Chemical generation of volatile hydrides is usually achieved by reaction of

\footnotetext{
* Author to whom correspondence should be addressed. (E-mail: roncevic@chem.pmf.hr)
} 
aqueous sample with tetrahydroborate salts which allows complete separation of analyte from the matrix. Consequently, it results in enhanced sensitivity and suppression of interferences.

Chemical vapour generation coupled to ICP-AES was applied in this work for the determination of tin content in samples with high content calcium carbonate matrix. In order to evaluate possible non-spectral interferences which could rise from complex sample matrix, the detection power and linearity of intensity measurements response were compared for standard aqueous and matrix matched solutions. The aim of study was to select the most appropriate analytical conditions for the tin determination in mollusks shell, since it was already known that they could incorporate different metals through biomineralization processes. ${ }^{6}$ The major input of tin into aquatic systems derives from its use in antifouling paints in the form of organotin compounds. ${ }^{7}$ Even though the use of antifouling paint is regulatory banned, ${ }^{8}$ there are still some harbor areas where the removal of old coatings may cause locally high concentrations of organotin compounds. ${ }^{9}$ A bioavailability and bioaccumulation studies based on speciation of organotin compounds from mussels tissue requires comprehensive analytical separation and sensitive detection, but their results are in great extent influenced by actual environmental conditions. Therefore, the data of total tin content in shell which was obtained more rapidly by described HG-ICP-AES method is valuable record in screening of accumulated longterm effects in environmental system.

\section{EXPERIMENTAL}

\section{Instrumentation}

A Teledyne Leeman Labs. (Hudson, NH, USA) Prodigy High Dispersion ICP system is used. The instrument is equipped with $40 \mathrm{MHz}$ "free-running" radiofrequency generator and echelle grating spectrometer with a largeformat programmable array detector (L-PAD). Sample introduction system which consisted of a glass cylonic spray chamber and a glass concentric nebulizer was connected to a three channel peristaltic pump and reaction coil of hydride generator (HG, Leeman Labs. Inc.). The dual-view torch for observing both axial and radial position was used. The sample solution uptake rate was adjusted on $0.9 \mathrm{~mL} \mathrm{~min}^{-1}$. The r.f. power of $1.3 \mathrm{~kW}$, and flow rates of argon (coolant $18 \mathrm{~L} \mathrm{~min}^{-1}$, auxiliary $0.8 \mathrm{~L}$ $\min ^{-1}$ ) were held constant in all measurements.

\section{Reagents and Solutions}

Single element standard solutions of $\mathrm{Sn}$ and $\mathrm{Ca} 1000$ $\mathrm{mg} \mathrm{L}^{-1}$ (Plasma Pure, Leeman Labs, Hudson, NH, USA) were used for the preparation of calibration standard solutions and control of plasma line positioning. Highpurity deionised water $(18 \mathrm{M} \Omega \mathrm{cm}$, Milli-Q Element system, Millipore, USA) was used for the dilution of reagent standards and samples. A fresh solution of $\mathrm{NaBH}_{4} 1.0 \% \mathrm{~m} / \mathrm{v}$ in $\mathrm{NaOH} 0.8 \% \mathrm{~m} / v$ was prepared for reduction of samples. Tartaric acid which serves as a reaction medium for hydride generation was prepared by dissolution of $10 \mathrm{~g}$ of solid compound in $1 \mathrm{~L}$ of water. The first set of calibration solutions of tin were prepared in the range of $0.1-10.0 \mathrm{mg} \mathrm{L}^{-1}$ by dilution with $1 \% \mathrm{~m} / \mathrm{v}$ tartaric acid solution to appropriate volume. Calibration blank contained only aqueous solution of tartaric acid. The second set of calibration solutions was prepared in the same manner with addition of $\mathrm{Ca}$ standard to final concentration of $160 \mathrm{mg} \mathrm{L}^{-1}$. The concentration of added standard matched the expected content of $\mathrm{Ca}$ in examined samples. Method of standard addition (MSA) included aliquots of dissolved samples in which a standard solution of tin was added. MSA solutions were diluted with $1 \% \mathrm{~m} / \mathrm{v}$ tartaric acid solution. The final concentration range in MSA sample solutions was $0.1-10.0 \mathrm{mg} \mathrm{L}^{-1}$ of tin.

\section{Measurements}

For the purpose of HG-ICP-OES measurements, all calibration standards and samples were mixed with a solution of $\mathrm{NaBH}_{4}$ by three-channel peristaltic pump at a rate of $0.9 \mathrm{~mL} \mathrm{~min}^{-1}$. Solutions were introduced into a reaction coil where stannane gas was generated and introduced into plasma through nebulizer and cyclonic nebulization chamber. Emission lines of tin were selected from image on L-PAD detector as the most prominent lines without spectral and background interferences. Additional argon purging of spectrometer optics was switched on before and during signal acquisition. Integration time was adjusted to $40 \mathrm{~s}$ and signal acquisition was repeated three times throughout measurements. The advantage of used ICP-AES instrument is the removal of matrix interferences by subtracting images of background signal. Therefore, calcium content in model solutions for background correction was adjusted to 160 $\mathrm{mg} \mathrm{L}^{-1}$ of $\mathrm{Ca}$ and a recorded spectral image was subtracted from spectral images of tin lines. The RF power and nebulizer gas flow rate were optimized to give the maximum intensity of $\mathrm{Sn}$ lines on L-PAD detector, i.e. $1300 \mathrm{~W}$ and $0.9 \mathrm{~L} \mathrm{~min}^{-1}$, respectively. Sample uptake delay before starting of intensity measurement was set on 50 seconds. This value was selected after collecting a signal by option of Time Resolved Analysis (TRA) of instrument software. The signals started to rise after 25 seconds and plateau of signals was reached after 50 seconds from aspiration start. 


\section{Samples and Sample Preparation}

Samples of Mytilus galloprovincialis were collected from different locations on east coast of Adriatic Sea during 2009. Each sample was consisted of whole mussel of almost equal length $(5-6 \mathrm{~cm})$ which is habitually reached in the second year of mussel growth. Before the samples were delivered into laboratory, the soft tissue was removed; shells were cleaned, dried and powdered in grinding mill.

Powdered shell samples of mussel Mytilus galloprovincialis were dried in drying oven at $105{ }^{\circ} \mathrm{C}$ before starting analytical procedures. An amount of $0.1 \mathrm{~g}$ of each pulverised sample was weighted with $0.0001 \mathrm{~g}$ of precision and placed in Teflon vessels of MWS-2 Microwave System Speedware (Berghof, Eningen, Germany). A volume of $5 \mathrm{~mL}$ of concentrated $\mathrm{HCl}$ was added and vessels were kept open for $30 \mathrm{~min}$ due to removal of carbon dioxide. The microwave digestion was conducted in three steps $\left(145^{\circ} \mathrm{C} / 15 \mathrm{~min} ; 180^{\circ} \mathrm{C} / 30 \mathrm{~min}\right.$; $\left.100{ }^{\circ} \mathrm{C} / 15 \mathrm{~min}\right)$. The clear remainder solutions were transferred into $25 \mathrm{~mL}$ volumetric flasks and diluted with high-purity deionised water. Before the HG-ICPAES measurements, samples were ten-fold diluted with tartaric acid solution. All samples and procedural blank samples were prepared as duplicates.

Control of accuracy for applied analytical procedure was performed by use of certified reference material of marine sediments NRCC MESS-3. Two control samples made in laboratory were also used; the first was PJSC (Pecten jacobaeus Standard Calcite) and the second CESA (Cerastoderma Standard Aragonite). This control samples were provided by courtesy of Centre of Marine Research, Institute Ruđer Bošković, Rovinj, Croatia. They consist of powdered shells of Pecten jacobaeus and Cerastoderma made of calcite and aragonite mineral of high purity which had already been confirmed by XRD method. The purity of samples was tested in MSA mode of measurement by addition of tin standard solution of $0.1 \mathrm{mg} \mathrm{L}^{-1}, 5 \mathrm{mg} \mathrm{L}^{-1}$ and $10 \mathrm{mg} \mathrm{L}^{-1}$ in digests of CESA and PJSC sample. Solutions of MESS-3, calcite and aragonite shell standards were prepared by the same digestion procedure in microwave oven as was described above.

\section{RESULTS AND DISCUSSION}

\section{Matrix Matching Calibration and Analytical Accuracy}

In order to evaluate the effects of calcium on tin emission, the two sets of calibration standards were measured by HG-ICP-AES method. The first set was represented by aqueous solutions with added tartaric acid which acts as interference retarding agens. ${ }^{10,11}$ The second set of solutions with the same concentration range of tin and tartaric acid additive was matrix-matched to contain the same calcium content as was expected for the shell samples. The precision of signal measurements expressed as relative standard deviation was established in the range $0.1-1.0 \%$ for both sets of calibration. A good linearity of calibration curves for all observed $\mathrm{Sn}$ lines was obtained $\left(R^{2}=0.9995-0.9999\right)$ for the first set of solutions. The calibration with matrix-matched solutions showed slightly worse linearity $\left(R^{2}=0.9951-\right.$ 0.9999). The method detection limits $\left(c_{L}\right)$ which were calculated using $3 \sigma$ criterion, i.e. the concentration equivalent to three times standard deviation $(3 \sigma)$ of the signal $(n=10)$ of the reagent blank solution, are given in the Table 1. The limits of quantification (LOQ) were calculated from calibration curves and expressed in $\mathrm{ng} \mathrm{g}^{-1}$ of sample mass.

The sensitivity of measurements in aqueous standards and matrix-matched standards should be examined from the obtained calibration curves which are shown in Figure 1. The effect of added calcium can be seen as slightly reduced emission intensity at emission lines $224.605 \mathrm{~nm}$ and $235.484 \mathrm{~nm}$. This reduction comprises $3 \%$ of intensity values in standard aqueous solution. The better sensitivity of signal was noted at $283.999 \mathrm{~nm}$ and $189.991 \mathrm{~nm}$ lines in both series of calibration. Comparison of detection capability of tin at most sensitive lines showed lower detection limit at ionic line of $189.991 \mathrm{~nm}$ than at atomic line of $283.999 \mathrm{~nm}$. Lower detection limits, good linearity in the observed range of concentrations, and the better precision of measurements favoured the determination of tin content at

Table 1. Selected tin emission lines, calibration linear coefficients and detection power in standard and matrix-matched calibration mode

\begin{tabular}{cccccccc}
\hline \multicolumn{2}{c}{$\lambda / \mathrm{nm}$} & $\begin{array}{c}\text { Standard } \\
\text { calibration }\left(R^{2}\right)\end{array}$ & $c_{L} / \mu \mathrm{L} \mathrm{L}^{-1}$ & $\mathrm{LOQ} / \mathrm{ng} \mathrm{g}^{-1}$ & $\begin{array}{c}\text { Matrix-matched } \\
\text { calibration }\left(R^{2}\right)\end{array}$ & $\mathrm{MM}_{L} / \mu \mathrm{g} \mathrm{L}{ }^{-1}$ & ${\mathrm{MM} \mathrm{LOQ} / \mathrm{ng} \mathrm{g}^{-1}}^{2}$ \\
\hline Sn II & 189.991 & 0.9995 & 1.9 & 6.4 & 0.9991 & 2.1 & 7.0 \\
Sn I & 224.605 & 0.9996 & 1.4 & 4.5 & 0.9951 & 1.9 & 5.9 \\
Sn I & 235.484 & 0.9998 & 6.3 & 20.0 & 0.9988 & 8.2 & 26.0 \\
Sn I & 283.999 & 0.9999 & 6.5 & 20.7 & 0.9999 & 8.5 & 22.7 \\
\hline
\end{tabular}




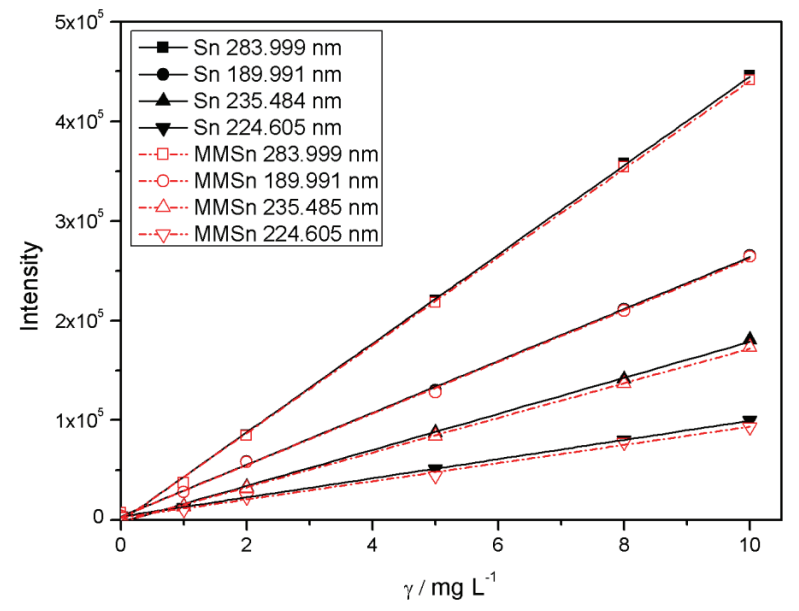

Figure 1. Calibration curves obtained by HG-ICP-AES in standard aqueous solutions and in matrix-matched solutions (MM with $160 \mathrm{mg} \mathrm{L}^{-1}$ of $\mathrm{Ca}$ ).

$189.991 \mathrm{~nm}$. The effects of Ca matrix on two prominent lines were almost negligible $(<1 \%)$. Considering that the background correction on tin lines was performed by subtracting spectra of matrix-matched solutions, the resulting reduction of signal intensity was not caused by any spectral interference. Hydride generation from solution with added interference-retarding tartaric acid provides a selective formation of stannane gas which enters into plasma. ${ }^{12}$ Thus, there is no need to perform extensive study of possible interfering effects. ${ }^{13}$ Such fine effects as we noted here are usually explained by slightly different transport properties of solution and generated vapour. ${ }^{11,14}$

The accuracy of analytical procedure was tested by certified reference material of marine sediments (NRCC MESS-3) with declared tin content of $2.50 \pm$ $0.52 \mathrm{mg} \mathrm{kg}{ }^{-1}$. ICP-AES measurements of tin content from dissolved sediment material by generation of volatile stannane gave the result of $2.52 \pm 0.05 \mathrm{mg} \mathrm{kg}^{-1}$ after standard calibration and $2.50 \pm 0.08 \mathrm{mg} \mathrm{kg}^{-1}$ after matrix matched calibration. The recovery of tin after hydrochloric acid digestion of reference material in microwave system was $100.08 \%$ and $100.00 \%$ which implies excellent agreement with declared value in both calibration modes.

\section{Analysis of Shell Samples}

It is already known that metal content in the molluscs shell is influenced by environmental conditions; metals are accumulated through biomineralization process, precipitation or adsorption from water. ${ }^{15-18}$ After incorporation into mineral structure they are not subjected to reproductive or physiological conditions, and kinetic of their removal is extremely slow comparing to soft tissue. ${ }^{19}$ Different mineralogical structure of shell layers implies incorporation of metals with different ionic radius into calcite or aragonite layer. ${ }^{20}$ Therefore, for the control of tin presence in rhombohedra calcite and

Table 2. Total tin content in shell samples determined by HG-ICP-AES

\begin{tabular}{rcccrr}
\hline No. & Sampling site & Description & $\begin{array}{c}\gamma(\mathrm{Sn}) \pm \sigma / \mu \mathrm{g} \mathrm{g}^{-1} \\
(n=6)\end{array}$ & $\begin{array}{c}\text { Statistical } \\
\text { Ranking }{ }^{(a)}\end{array}$ & $\begin{array}{c}\text { Ranking } \\
\text { Percentage }\end{array}$ \\
\hline 1 & Zablaće & Harbour, city waste and sewage & $0.643 \pm 0.021$ & 6 & $66.60 \%$ \\
2 & Srima & Fishing port & $0.611 \pm 0.011$ & 8 & $53.30 \%$ \\
3 & Jadrija & Non-urban area, yachting area & $0.598 \pm 0.013$ & 9 & $46.60 \%$ \\
4 & Martinska & Estuary (r. Krka), marina & $0.718 \pm 0.032$ & 1 & $100.00 \%$ \\
5 & Mala Klačina & Bay, yachting area & $0.571 \pm 0.010$ & 10 & $40.00 \%$ \\
6 & Sv. Ivan & Agriculture, estuary (r. Neretva) & $0.706 \pm 0.022$ & 2 & $93.30 \%$ \\
7 & Gruž & Harbour, city waste & $0.655 \pm 0.015$ & 4 & $80.00 \%$ \\
8 & Omiš & Fishing port, estuary (r. Cetina) & $0.674 \pm 0.027$ & 3 & $86.60 \%$ \\
9 & Rijeka Dubrovačka & Marina, estuary (r. Dubrovačka) & $0.554 \pm 0.041$ & 11 & $33.30 \%$ \\
10 & Ploče & Harbour, agriculture, estuary (r. Neretva) & $0.552 \pm 0.029$ & 12 & $26.60 \%$ \\
11 & Srima 2 & Fishing port & $0.549 \pm 0.018$ & 13 & $20.00 \%$ \\
12 & Bajlo & Non-urban area, yachting area & $0.511 \pm 0.024$ & 16 & $0.00 \%$ \\
13 & Bačvice & Urban area, recreational & $0.632 \pm 0.021$ & 7 & $60.00 \%$ \\
14 & Jadrija 2 & Non-urban area, yachting area & $0.547 \pm 0.011$ & 14 & $13.30 \%$ \\
15 & Vranjic & Industrial waste & $0.653 \pm 0.014$ & 5 & $73.30 \%$ \\
16 & Martinska 2 & Estuary (r. Krka) & $0.522 \pm 0.027$ & 15 & $6.60 \%$ \\
\hline
\end{tabular}

(a) Mean: $0.606 \mu \mathrm{g} \mathrm{g}^{-1}$, Median: $0.6045 \mu \mathrm{g} \mathrm{g}{ }^{-1}$, Standard Deviation: $0.065099 \mu \mathrm{g} \mathrm{g}^{-1}$, Sample Variance: 0.004238, Kurtosis: -1.14055, Skewness: 0.228415, Range: $0.207 \mu \mathrm{g} \mathrm{g}^{-1}$, Minimum: $0.511 \mu \mathrm{g} \mathrm{g}^{-1}$, Maximum $0.718 \mu \mathrm{g} \mathrm{g}{ }^{-1}$, Count 16 . 
orthorhombic aragonite the analysis of two laboratory samples was performed. Samples were represented by powdered shells of Pecten jacobaeus Standard Calcite (PJSC) and Cerastoderma Standard Aragonite (CESA) which mineralogical purity was confirmed by X-ray diffraction. They were tested on tin impurities by HGICP-AES method using the mode of standard addition (MSA). Linear coefficients in MSA operation mode comprised the same values $\left(R^{2}=0.9996\right)$ at each observed line. Calculation of tin concentration was made using the intensity values on the most prominent ionic line at $189.991 \mathrm{~nm}$. The obtained reference values for tin content were $0.11 \pm 0.01 \mu \mathrm{g} \mathrm{g}^{-1}$ in PJSC and 0.17 $\pm 0.02 \mu \mathrm{g} \mathrm{g}^{-1}$ in CESA sample. The measured values can be related to the fact that ion with smaller radius than $\mathrm{Ca}$ (i.e. $\mathrm{Fe}, \mathrm{Mn}, \mathrm{Cu}$ and $\mathrm{Zn}$ ) can easily be incorporated into calcite structure and ion with greater radius $(\mathrm{Cd}, \mathrm{Ba}$ and $\mathrm{Pb})$ can be incorporated into aragonite structure. ${ }^{15,20}$ Consequently, radius of tin ion is slightly smaller than radius of lead and hence is prevalent in CESA sample rather than in PJSC sample.

Tin content in shell samples determined by HGICP-AES method is presented in Table 2. Samples of Mytilus galloprovincialis were collected at several locations along the east coast of the Adriatic Sea, especially near the hot-spots of possible anthropogenic impact on the marine environment i.e. near harbours, city waste outlets, industrial zones, and also near the estuaries of several rivers. Description of each sampling site is also presented in Table 2. The results of tin measurements in M. galloprovincialis shell samples were corrected by subtracting the value of $0.14 \mu \mathrm{g} \mathrm{g}^{-1}$ which was the average of tin concentration measured form CESA and PJSC samples. The correction was performed because both mineralogical forms, i.e. calcite and aragonite, build the shell of investigated molluscs. The obtained range of total tin content in shell samples lay between 0.511 $\mu \mathrm{g} \mathrm{g}^{-1}$ and $0.718 \mu \mathrm{g} \mathrm{g}^{-1}$. Statistical description of results returns the negative excess kurtosis $(-1.14055)$ and positive skewness $(0.228415)$ of data set which indicates the relatively flat distribution of tin in collected samples. By ranking the measured tin contents and the sampling sites it can be observed that samples which show the concentration above the median values (No. 4, 6, 8, 7, 15, 1, 13, 2) were collected from sites near aluminium processing industry centre, harbours, and fishing ports.

Calculated total Sn concentrations have also reported in some recent studies which concern butyltin and octyltin speciation in M. galloprovincialis tissue and seawater. ${ }^{21}$ In the malformed shell chambers of marine bivalve species Ostrea edulis it was found by X-ray photoelectron spectroscopy (XPS) and X-ray microprobe (EDX), that tin is present in amounts of $0.1-0.2 \%$. Such amount indicates heavy TBT pollution and environmentally induced mechanisms of metal incorporation. ${ }^{22,23}$ For the entire Croatian Adriatic Coast it was ranged between 0.46 to $27.98 \mathrm{ng} \mathrm{L}^{-1}$ for seawater and between 6 to $1675 \mathrm{ng} \mathrm{g}^{-1}$ for mussels. ${ }^{24}$ It was demonstrated that Mytilus species can rapidly metabolize organotin compounds from antifouling reagents. The range of estimated bioconcentration factor for this species (2000-90000) suggests that tin occurrence in tissue samples shows huge temporal and spatial variations. ${ }^{25}$ Comparison of tin content in shell and tissue must account complex relations between metabolism and biomineralization processes which is still challenging problematic. Therefore, the total tin content determined in shell samples is appreciable record especially by knowing that slow growth and long life of mussels provide a time integrated indication of environmental contamination. It could also be very useful for rapid screening and recording of long term effects at monitoring sites.

\section{CONCLUSIONS}

Quantitative determination of tin content in calcium carbonate matrix has been utilised by HG-ICP-AES method. Chemical vapour generation was achieved by reduction of sample solutions with sodium borohydride in tartaric acid medium. Selective generation of stannane vapour was detected at low concentration levels and without spectral interferences on all observed lines. Comparison of two modes of calibration showed that intensity emission on chosen lines was slightly reduced in solutions with added calcium than in standard aqueous matrix. It was established that emission line at $189.991 \mathrm{~nm}$ was less influenced regarding to detection power and sensitivity. However, matrix matched calibration standards is recommendable for sample analysis due to the compensation of non-spectral effects caused by different transport properties. Control of analytical preparation and HG-ICP-ES measurement procedure by certified reference material showed excellent recoveries of tin. Analysis of laboratory pure shells samples showed the presence of tin at low concentration levels in calcite and aragonite structures. The method was also applied in determination of tin content in shells of Mytilus galloprovincialis which were collected along the Croatian Adriatic Coast. The results obtained by HGICP-AES analysis of carbonate matrix samples show relatively flat distribution of tin but also suggest several hot-spots of possible anthropogenic influence on environmental contamination.

Acknowledgements. This work was performed as collaboration within the project "Understanding and manipulating enzymatic and proteomic processes in biomineralization" COST Action TD0903. 


\section{REFERENCES}

1. M. Grotti, M. L. Abelmoschi, F. Soggia, and R. Frache, Anal. Bioanal. Chem. 375 (2003) 242-247.

2. M. Thompson and M. H. Ramsey, Analyst 110 (1985) 14131422.

3. L. Paama and P. Peramaki, Atom. Spectrosc. 18 (1997) 119-121.

4. M. Stepan, P. Musil, E. Poussel, and J. M. Mermet, Spectrochim. Acta Part B 56 (2001) 443-453.

5. A. Krejcova, T. Cernohorsky, and M. Pouzar, Microchim. Acta 156 (2007) 271-275.

6. D.M. Lyons, D. Medaković, Ž. Skoko, S. Popović, S. Rončević, L. Pitarević Svedružić, and I. Karniš, Cryst. Growth Des. 9 (2009) 3671-3675.

7. H. Rüdel, Ekotoxicol. Environ. Saf. 56 (2003) 180-189.

8. M. A. Champ, Sci. Total Environ. 258 (2000) 21-71.

9. A. X. Yi, K. M. Y. Leung, M. H. W. Lam, J. S. Lee, and J. P. Giesy, Chemosphere 89 (2912) 1015-1025.

10. A. D'Ulivo, Spectrochim. Acta Part B 65 (2010) 360-375.

11. M. Grotti and C. Lagomarsino, R. Frache, J. Anal. Atom. Spectrom. 20 (2005) 1365-1373.

12. H. Wiltsche, I. B. Brenner, G. Knapp, and K. J. Prattes, J. Anal. Atom. Spectrom. 22 (2007) 1083-1088.

13. N. Velitchkova, E. N. Pencheva, N. Daskalova, Spectrochim. Acta Part B $\mathbf{5 9}$ (2004) 871-882.
14. C. Agatemor and D. Bauchemin, Anal. Chim. Acta 706 (2011) 66-83.

15. C. M. Davidson, M. D. Gibson, E. Hamilton, B. H. MacGillivray, J. Reglinski, and E. Rezabal, Chemosphere 58 (2005) 793-798.

16. A. Cravo, P. Foster, C. Almeida, R. Company, R. P. Cosson, and M. J. Bebianno, Environ. Int. 33 (2007) 609-615.

17. B. E. Rosenheim, P. K. Swart, and S. R. Thorrold, Paleogeogr. Paleoclim. Paleoecol. 228 (2005) 109-129.

18. V. K. Mubiana and R. Blust, Mar. Env. Res. 63 (2007) 219-235.

19. M. Lares, L. E. Rivero, and M. A. Huerta-Diaz, Mar. Poll. Bull. 50 (2005) 1373-1381.

20. F. Renard, G. Montes-Hernandez, E. Ruiz-Agudo, and C.V. Putnis, Chem. Geo. 340 (2013) 151-161.

21. A. Sousa, T. Ikemoto, S. Takahashi, C. Barosso, and S. Tanabe, Mar. Poll Bul. 58 (2009) 1130-1136.

22. D. Medaković, P. Traverso, C. Bottino, and S. Popović, Surf. Interface Anal. 38 (2006) 313-316.

23. D. Medaković and S. Popović, Unusual Crystal Formation in Organisms - Exceptions that Confirm Biomineralization Rules, in: E. Borisenko (Ed.), Crystallization and Materials Science of Modern Artificial and Natural Crystals, InTech, Rijeka, 2012, pp. 157-184.

24. M. Furdek, M. Vahčić, J. Ščančar, R. Milačić, G. Kniewald, and N. Mikac, Mar. Poll Bul. 64 (2012) 189-199.

25. M. T. Nemanič, R. Milačić, and J. Ščančar, Wat. Air Soil Poll. 196 (2009) 211-224. 